\title{
The Impact of Coffee on Health
}

Author

Karen Nieber

Affiliation

University of Leipzig, Institute of Pharmacy, Leipzig

Key words

adenosine receptors, caffeine, chlorogenic acid, coffee, cardiovascular system, diabetes, IBD, liver

received April 27, 2017

revised May 29, 2017

accepted June 20, 2017

Bibliography

DOI https://doi.org/10.1055/s-0043-115007

Published online July 4, 2017 | Planta Med 2017; 83: 1256-

1263 @ Georg Thieme Verlag KG Stuttgart · New York I

ISSN 0032-0943

Correspondence

Prof. Dr. Karen Nieber

University of Leipzig, Institute of Pharmacy

Brüderstr. 34, 04103 Leipzig, Germany

Phone: + 4917631123917 , Fax: + 4939200787646

nieber@rz.uni-leipzig.de

\section{ABSTRACT}

Coffee is one of the most popular and widely consumed beverages worldwide due to its stimulating effects on the central nervous system as well as its taste and aroma. Coffee is a complex mixture of more than 800 volatile compounds whereas caffeine and chlorogenic acids are the most common compounds. During the last years, coffee has progressively moved to a less negative position on health due to its better-known pharmacology. Caffeine, e.g., in a cup of coffee, appears to exert most of its effects through an antagonism of the adenosine receptors. Novel approaches in epidemiological studies and experimental researches suggest that coffee consumption may help to prevent several chronic diseases, including type 2 diabetes mellitus and liver disease. Most prospective cohort studies have not found coffee consumption to be associated with a significantly increased cardiovascular disease risk. There is also evidence that decaffeinated coffee may, in some respect, have similar benefits as regular coffee, indicating that besides caffeine other components contribute to the health protecting effects. For adults consuming moderate amounts of coffee (3-4 cups/d providing $300-400 \mathrm{mg} / \mathrm{d}$ of caffeine), there is little evidence of health risks and some evidence of health benefits. This review provides up-to-date information about coffee on health. Topics addressed include the cardiovascular system, liver diseases, and diabetes as well as gastrointestinal disorders.

\section{Introduction}

In 2016/17, the production of roar coffee amounted to about 151.62 million $60 \mathrm{~kg}$ bags [1], and it is estimated that 2.25 billion cups of coffee are consumed each day worldwide [2]. Coffee is served internationally and most countries have developed its own preferences about how to prepare and present it.

The history of coffee goes at least as far back as the 10th century, with a number of legends surrounding its use. The native (undomesticated) origin of coffee is thought to have been Ethiopia. The earliest substantiated evidence of either coffee drinking or knowledge of the coffee tree is from the 15th century, in the Sufi monasteries of Yemen. By the 16th century, it had reached the rest of the Middle East, South India, Persia, Turkey, and Northern Africa. Coffee then spread to the Balkans, Italy, and the rest of Europe, to Indonesia and then to America [3]. Although coffee was introduced in Europe only a few hundred years ago, con- sumption of this beverage now occupies a significant place in our national cultures.

Coffee is taken as a brewed beverage that is prepared from the roasted seeds of a bush of the genus Coffea. The coffee beans are contained in berries that, once matured, are processed and dried. The two main species are Coffea Arabica (coffee Arabica) and Coffea canephora (coffee Rustica). They have a large production history and an important role both in the global market and researches [4].

The high consumption of coffee may have a substantial effect on public health. Therefore, it is no wonder that coffee stimulates the interest of researchers and clinicians. In PubMed in May 2017, the term "Coffee" resulted in 12583 hits including 998 reviews and 1666 clinical trials. Nevertheless, the impact of coffee intake on chronic diseases has been a matter of debate in the last two decades, with some conflicting results due the retrospective nature of most of the studies, although coffee has progressively moved to a less negative position due to its better-known phar- 


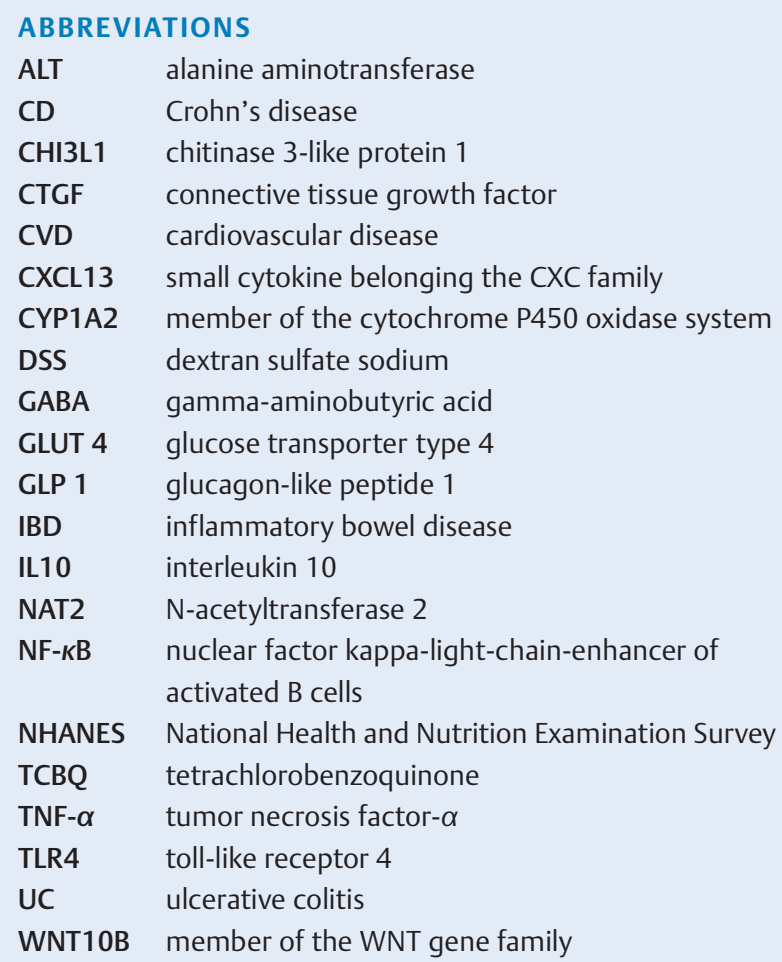

macology. The novel approaches in epidemiological data and experimental researches suggest that consumption of coffee is associated with a reduced risk of several chronic and degenerative diseases. This paper reviews the most significant protective actions of coffee on the cardiovascular system, liver diseases, and diabetes as well as gastrointestinal disorders, especially IBD. Clinical and experimental studies are discussed and, if possible, the role of caffeine and polyphenols is presented.

\section{Bioactive Components in Coffee}

Coffee includes a complex mixture of compounds. The particular profile of compounds depends on coffee variety, roasting, and processing. Caffeine has been perhaps the most widely known compound and is the most investigated component of coffee. When green coffee beans are roasted under high temperatures, chemical reactions between amino acids and carbohydrates, known as Maillard reactions, create a number of unique components. Additionally, coffee is abundant in polyphenols like chlorogenic acids. The main chlorogenic acid in coffee is 5-caffeoylquinic acid, although other caffeoylquinic, feruloylquinic, and dicaffeoylquinic acids are present in significant quantities [5]. Phenolic metabolites of chlorogenic acids have been studied for potential bioefficacy, and controversy still remains as the results are not entirely clear [6,7]. Only a few studies have investigated the bioavailability of coffee phenolic and chlorogenic acids due to the complex metabolic pathways in humans $[8,9]$. Chlorogenic acids may be transformed into phenolic acids (caffeic, ferulic, and isoferulic moieties) and, subsequently, into colonic metabo- lites (dihydrocaffeic and dihydroferulic acids). With extensive conjugation at the level of the intestine and the liver, many different metabolites (aglycone, sulfate, glucuronide, and methyl) could then be identified from a single cup of coffee. Lactones, diterpenes, including cafestol and kahweol, niacin, and the vitamin B3 precursor trigonellin are also present in coffee ( $\bullet$ Fig. 1$)$. Cafestol and kahweol found in coffee oil have shown antioxidant activity in cell models and mice models that involved triggering the upregulation of key antioxidant enzymes $[10,11]$. On the other hand, the two diterpenes are the main cholesterol-rising compounds in coffee. They are retained in part by paper filters, but are preserved when coffee is directly prepared by boiling the ground beans [12]. Moreover, coffee is rich in vitamin B3, magnesium, and potassium.

\section{Pharmacokinetics and Mode of Action of Caffeine}

Caffeine is the most widely consumed behaviorally active substance in the world. It is present in a number of dietary sources, i.e., tea, coffee, cocoa beverages, and chocolate bars as well as soft and energy drinks ( $\triangleright$ Table 1 ). Caffeine was first extracted from cocoa beans into its purest form, a white powder, in the 1820 s by the German Scientist Friedrich Ferdinand Runge. Caffeine is contained in more than sixty plants, which is a remarkable number, thus it has been hypothesized that caffeine was originally a minor nutrient, not essential for the plant, but extremely useful as a pesticide. In fact, caffeine is toxic for several insects and animals, especially herbivores. Through caffeine the plant may defend itself and have a better chance of survival. In this view, caffeine can be considered as a "co-evolutionary protecting agent" [13]. The amount of this natural alkaloid in coffee is influenced by the method of coffee preparation, and amounts between 65 to $120 \mathrm{mg}$ of caffeine have been reported to be contained in a normal cup of coffee, whereas Arabica coffee normally contains less caffeine than the Robusta variety [14]. Soft drinks typically contain about 30 to $60 \mathrm{mg}$ of caffeine per serving. By contrast, energy drinks contain as much as $80 \mathrm{mg}$ of caffeine per serving ( $\triangleright$ Table 1). The caffeine in these drinks either originates from the ingredients used or is an additive derived from the product of decaffeination or from chemical synthesis $[15,16]$.

Caffeine is completely absorbed by the stomach and small intestine within 45 min of oral ingestion. The hydrophobic properties of caffeine allow its passage through all biological membranes and the peak plasma concentration is reached within 15-20 min after oral ingestion in humans [15]. Caffeine is metabolized in the liver by the cytochrome P450 oxidase enzyme system, specifically the CYP1A2 enzyme into three primary metabolites: paraxanthine (84\%), theobromine (12\%), and theophylline (4\%) [17]. Another enzyme involved in caffeine clearance is the NAT2, whose function is to catalyze the transformation of a broad range of xenobiotics [18]. This enzyme has previously been studied with relation to the risk of Parkinsons's disease and in gene-environment interaction studies [19], but with mixed results.

The half-life time of caffeine varies widely among individuals depending on such factors as age, liver function, pregnancy, some 


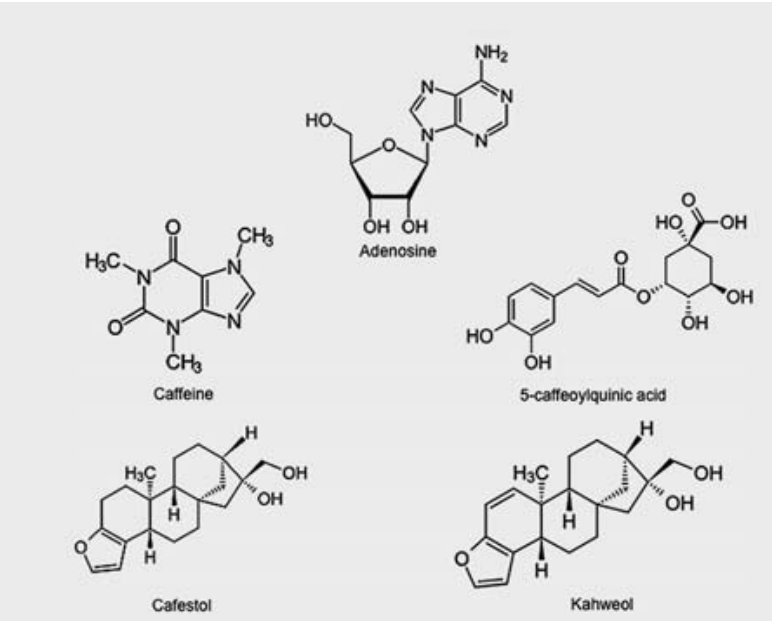

- Fig. 1 Chemical structures of adenosine and major biologically active compounds in coffee.

concurrent medications, and the level of enzymes in the liver needed for caffeine metabolism. In healthy adults, caffeine's half-life time is approximately $3-4 \mathrm{~h}$. In women taking oral contraceptives, this is increased to $5-10 \mathrm{~h} \mathrm{[20]}$ and in pregnant women the half-life time is roughly $9-11 \mathrm{~h}$ [21]. In infants and young children, it may be longer than in adults [15].

The principal mode of action of caffeine at doses in normal human consumption is as an antagonist of adenosine receptors. Adenosine receptors have been cloned, namely, A1, A2A, A2B, and $A 3$. $A 1$ and $A 3$ receptors preferentially couple to $G i$ proteins and inhibit adenylate cyclase, while A2A and A2B couple to Gs and stimulate production of cyclic AMP (cAMP) [21]. These receptors are widely expressed in the human body and have been implicated in several biological functions, both physiological and pathological. These include cardiac rhythm and circulation, lipolysis, renal blood flow, immune function, sleep regulation, and angiogenesis as well as inflammatory diseases, ischemia-reperfusion, and neurodegenerative disorders [22]. The caffeine molecule is structurally similar to adenosine and is able to potently block adenosine effects on $\mathrm{A} 2 \mathrm{~A}$ and $\mathrm{A} 1$ receptor subtypes already at the low concentration achieved after a single cup of coffee. Twenty times higher concentrations are required to inhibit cyclic nucleotide breakdown via inhibition of phosphodiestarases. To block $\mathrm{GABA}_{\mathrm{A}}$ receptors 40 times higher and to mobilize intracellular calcium stores via activation of ryanodine receptors, 100 times higher concentrations are needed [23]. These high concentrations of caffeine are unlikely to be reached in human by normal use of coffee [15]. For children and young adults, the primary sources of caffeine are soft drinks and teas, while for adults aged 25 and older, it is mostly derived from coffee. Interestingly, people in Asia mainly drink tea instead coffee.

\section{Effects of Coffee on the cardiovascular System}

Considerable controversy exists regarding the association between coffee consumption and CVD risk. The relationship between coffee consumption and the risk of coronary heart disease was first studied in the 1960s, given that the prevalence of coffee drinking and CVD were both high in Western countries [24]. Since 2000 , the association between coffee consumption and other CVD outcomes such as stroke, heart failure, and total CVD mortality has also been more frequently studied and summarized in meta-analyses [25-27]. These meta-analyses did not support an association between coffee consumption and a higher CVD risk, but the shape of the association remains uncertain. Interestingly, a meta-analysis published in 2014 [28] concluded that moderate coffee consumption (3-5 cups/day) was associated with a lower CVD risk, and heavy coffee consumption ( $\geq 6$ cups/day) was neither associated with a higher nor a lower risk of CVD. A further meta-analysis [29] has also showed that heavy coffee consumption was not associated with risk of CVD mortality. In contrast, the cohort study by Liu et al. [30] found that 4 cups per day of coffee consumption was associated with increased mortality, but the association was only significant for participants under 55 years of age. The results from this study contradict those from other metaanalyses and the majority of studies in the literature. Possible reasons for the discrepancy may be a relatively small size, lack of updated dietary assessment, and subgroup analysis in Liu's study. In addition, coffee brewing methods were not assessed in the included studies.

The question remains whether mechanisms lower the risk of CVD. Pharmacological studies have confirmed that A1 receptor activation has a number of effects in the cardiovascular system, including a reduction in heart rate and atrial contractility, and the attenuation of the stimulatory actions of catecholamines on the heart, and the A2A receptors are involved in vasodilation in the aorta and coronary artery [31]. The blockade of these receptors by caffeine can contribute to the protective effect of coffee in CVD. Apart from caffeine, further studies suggested the involvement of other components confirmed by results from studies with unfiltered and paper-filtered coffee [32] or caffeinated and decaffeinated coffee [33]. Chlorogenic acids and their metabolites, for example, attenuate oxidative stress (reactive oxygen species), which leads to the benefit of blood pressure reduction through improved endothelial function and nitric oxide bioavailability in the arterial vasculature [34]. It is concluded that the available evidence, although limited, allows for stating that there is no clinical basis for associating moderate coffee intake with an increased risk of cardiovascular diseases, including stroke [35]. Not only caffeine but also other components of coffee may contribute to the cardiovascular effects.

\section{Coffee and Type 2 Diabetes}

Coffee has recently received scientific attention as a current epidemiologic, and in vivo studies have revealed its health benefits against metabolic disorders, especially type 2 diabetes [36]. An 
- Table 1 Caffeine content chart (according to data from [16]).

\begin{tabular}{|c|c|c|c|}
\hline \multicolumn{2}{|l|}{ Item } & \multicolumn{2}{|c|}{ mg of caffeine } \\
\hline & & \multirow{2}{*}{$\begin{array}{l}\text { Typical } \\
85\end{array}$} & \multirow{2}{*}{$\begin{array}{l}\text { Range } \\
65-120\end{array}$} \\
\hline Coffee (240 mL) & Brewed, drip method & & \\
\hline & Instant & 75 & $60-85$ \\
\hline & Decaffeinated & 3 & $2-4$ \\
\hline & Espresso (30 mL) & 40 & $30-50$ \\
\hline \multirow[t]{4}{*}{ Teas (240 mL) } & Brewed, major U. S. brands & 40 & $20-90$ \\
\hline & Brewed, imported brands & 60 & $25-110$ \\
\hline & Instant & 28 & $24-31$ \\
\hline & Iced & 25 & $9-50$ \\
\hline \multicolumn{2}{|c|}{ Soft drinks (e.g. Cola 360 mL serving) } & 40 & $30-60$ \\
\hline \multicolumn{2}{|c|}{ Energy drinks (250 mL serving) } & 80 & $50-160$ \\
\hline \multicolumn{2}{|c|}{ Cocoa beverage ( $240 \mathrm{~mL})$} & 6 & $3-32$ \\
\hline \multicolumn{2}{|c|}{ Chocolate milk beverage ( $250 \mathrm{~mL}$ serving) } & 5 & $2-7$ \\
\hline \multicolumn{2}{|c|}{ Solid Milk chocolate (30 mL serving) } & 6 & $1-15$ \\
\hline \multicolumn{2}{|c|}{ Solid Dark chocolate, semi-sweet (30 mL serving) } & 20 & $5-35$ \\
\hline \multicolumn{2}{|c|}{ Baker's chocolate (30 mL serving) } & 26 & 26 \\
\hline \multicolumn{2}{|c|}{ Chocolate flavored syrup (30 mL serving) } & 4 & 4 \\
\hline
\end{tabular}

inverse correlation has been confirmed in most but not all studies. Therefore, an updated systematic review and a dose-response meta-analysis of all available data on the correlation of both caffeinated and decaffeinated coffee consumption with the risk of type 2 diabetes have been published in 2014 by Ding et al. [37]. The systematic review and meta-analysis based on 1109272 study participants and 45335 cases of type 2 diabetes demonstrate a robust inverse correlation between coffee consumption and the risk of diabetes. Compared with no coffee consumption, 6 cups/day of coffee was associated with a $33 \%$ lower risk of type 2 diabetes. The correlation was consistent for men and women [37]. By contrast, a multiethnic cohort study [38] suggested that the protective effect of coffee intake was stronger for women (34\% lower diabetes risk) than for men (14\% lower diabetes risk). The discrepancy may be due to the coffee intake assessment through self-reported dietary questionnaires. Misclassification, therefore, cannot be excluded. A further aim of Ding's systematic review [37] was to compare the effects of caffeinated and decaffeinated coffee consumption and the risk of type 2 diabetes. Decaffeinated coffee consumption was associated with the same level of protection as seen for caffeinated coffee and therefore confirmed previous findings of the European Prospective Investigation into Cancer and Nutrition (EPIC)-Germany study [39], which reported a $23 \%$ lower incidence for caffeinated and a $30 \%$ lower risk for decaffeinated intake of $\geq 4$ cups/day. It remains unclear, however, by which mechanism(s) the diabetes-preventive effect is brought about. There is evidence for both increased insulin secretory responsiveness and increased insulin sensitivity [40]. Coffee appears to act primarily, if not exclusively, through postprandial, as opposed to fasting, glucose homeostasis [41].
Studies observed a protective effect of decaffeinated coffee pointing to a relevant role of constituents other than caffeine, such as polyphenols, which are a major source of antioxidants in the Westernized diet $[42,43]$. As seen in knockout mice (Lepr $/ \mathrm{db})$, chlorogenic acid inhibited gluconeogenesis by affecting expression and activity of enzyme glucose-6-phosatase. Moreover, it improved skeletal muscle glucose uptake by increasing expression and translocation of GLUT 4. A 2.5-fold increase in glucose transport was described as an additive action with insulin [44]. Polyphenols in coffee stimulate GLP 1, which is a major intestinal hormone that activates glucose-induced insulin secretion from $\beta$-cells [45]. Prolonged activation of the GLP-1 signal has been shown to attenuate diabetes in animals and human subjects. This hypothesis has been confirmed by studies suggesting that polyphenols in coffee bean extract may bring an additive effect in decreasing body weight gain and increasing insulin sensitivity [46]. These beneficial effects are possibly due to the downregulation of genes associated with WNT10B- and galanin-mediated adipogenesis and the TLR4-mediated proinflammatory pathway as well as stimulation of GLUT4 translocation to the plasma membrane in white adipose tissue of mice [47]. So far, coffee has consistently been inversely associated with type 2 diabetes, and polyphenols, among other bioactive compounds, are the best candidates to be responsible for the beneficial actions.

\section{Coffee and Liver Diseases}

There is increasing evidence in favor of protective effects of coffee consumption in the development and progression of liver disease due to various causes. The clinical evidence of benefit of coffee 
consumption in hepatitis B and C, as well as nonalcoholic fatty liver disease and alcoholic liver disease, has been reviewed by Wadhawan and Anand in 2016 [48] and for hepatic fibrosis and cirrhosis by Liu et al. in 2015 [49]. The two meta-analyses clearly indicated that coffee intake of more than 2 cups per day in patients with preexisting liver disease is associated with a lower incidence of fibrosis and cirrhosis, lower hepatocellular and carcinoma rates, as well as decreased mortality. In favor of this protection, two recent population-based studies, the NHANES I and III [50-52], have reported that higher coffee consumption ( $>2$ cups per day) was associated with a lower risk of elevated ALT levels by $44 \%$ and a lower risk of chronic liver disease compared to non-coffee drinkers. Additionally, a recent large cohort study [53] of 330 patients with alcoholic and non-alcoholic cirrhosis showed a strong inverse relationship between coffee drinking (> 4 cups per day) and elevated serum enzyme levels, especially in those who drank large quantities of alcohol. Moreover, coffee consumption decreased liver stiffness, which may indicate less fibrosis and inflammation in patients with nonalcoholic fatty liver disease, and hepatitis C and B virus infection [54]. Although coffee consumption has been associated with a reduced frequency of liver disease, it is unclear whether the effect is from caffeine or other components. The beneficial effects of caffeine against liver fibrosis have been demonstrated by several studies using standard rodent models of experimental liver fibrosis. In almost every study, ingestion of coffee/caffeine blocked toxin-induced liver fibrosis/cirrhosis [55]. In particular, in experimental models of fibrosis, caffeine was shown to inhibit hepatic stellate cell activation by blocking $\mathrm{A} 2 \mathrm{~A}$ receptors, and emerging evidence indicates that caffeine might also favorably impact angiogenesis and hepatic hemodynamics. Successively, Gressner et al. [56] have shown that caffeine inhibits TGF- $\beta$-induced CTGF expression in hepatocytes. TGF- $\beta$ levels are reduced by coffee and caffeine administration to rats subjected to chemical-induced liver fibrosis $[52,57,58]$. On the other hand, Vitaglione et al. [59] reported that consumption of decaffeinated espresso coffee was able to reduce not only liver steatosis but also inflammation and fibrosis in rats. It is therefore suggested that caffeine in coffee is not essential and that specific coffee components contribute to the hepatoprotective effect [ 37 , $60,61]$. Chlorogenic acid possesses a hepatoprotective nature [62]. In a recent study [63] conducted on TCBQ-induced liver damage in mice, the acid pretreatment seems to be effective in suppressing TCBQ-induced oxidative stress, therefore possessing a hepatoprotective nature. Additionally, chlorogenic acid reduced liver fibrosis and the expression of collagen I and III. These rats displayed reduced concentrations of VEGF, TGF- $\beta$, and $\alpha$-smooth muscle actin [64]. The diterpenes cafestol and kahweol may offer protective effects against aflatoxin B1-induced liver damage in rats and in hepatocyte cultures [58,65]. Cafestol and kahweol may also induce the synthesis of glutathione, which has a role in detoxification and the prevention of liver damage. Taken together, a growing body of literature has consistently shown an inverse relationship between coffee consumption and liver diseases. However, there are not enough data to make firm conclusions about the relative importance of caffeine or other components within coffee in the development and progression of liver disease.

\section{Coffee and inflammatory Bowel Disease}

Studies to date suggest that there is no association between coffee consumption and the risk of dyspepsia [66], gastroesophagal reflux disease [67], peptic ulcers [68], gastritis, and stomach cancer $[69,70]$. People with IBD are coffee users as well, but the question remains as to whether coffee consumption is safe for people living with a chronic digestive disease. IBD consists of two major forms, CD and UC. In a study performed by $\mathrm{Ng}$ et al. [71], coffee had a protective effect against UC development. Another report studying 41836 postmenopausal women for 15 years showed that high coffee consumption is inversely correlated to the severity of inflammatory diseases [72]. It is well known that the herbal mixture of myrrh, dry extract of chamomile flowers, and coffee charcoal has anti-inflammatory and antidiarrheal properties. In a randomized, double-blind, double-dummy study [73], 96 patients with inactive UC were randomized to receive either the herbal preparation or mesalazine over a 12-month period. There was no significant difference in the relapse rate between the two groups. No significant differences were also shown in relapse-free time, endoscopy, and fecal biomarkers. In vitro, the herbal mixture influenced gene expression of activated human macrophages within the cytokine/chemokine signalling pathway. Particularly, chemokine gene expression was suppressed. Subsequently, the production of CXCL13 (which controls the organization of B cells within follicles of lymphoid tissues) and, to a minor extent, cytokine TNF- $\alpha$ were inhibited, whereas IL10 release from activated macrophages was enhanced by coffee charcoal extracts [74]. In vivo, mice treated with caffeine $(2.5 \mathrm{mM}$; equivalent to the concentration of caffeine in 2-3 cups of coffee) displayed a delayed response towards DSS-induced colitis, characterized by lower body weight loss and clinical and histological scores. Bacterial translocation into other organs and proinflammatory cytokine production were also reduced in the caffeine-treated mice with DSS-induced colitis. Caffeine treatment also resulted in the loss of CHI3L1-associated signalling pathway activation [75]. The disease-associated $\mathrm{CHI} 3 \mathrm{~L} 1$ expression was also observed in colonic tissue samples obtained from CD and UC patients, but was undetected in normal control individuals [76].

It is, however, considered that the effects of coffee are not exclusively due to caffeine but seem to be linked with other specific constituents [77]. Chlorogenic acid displayed a significant anti-inflammatory activity in a well-established mouse model of experimental colitis, as evidenced by a reduction of the macroscopic damage score, myeloperoxidase activity, and inhibition of the NF- $\kappa$ B dependent pathway [78]. Apart from these, the inhibition of cyclooxygenase-2, inducible nitric oxide synthase (iNOS) with the lack of a cytotoxic effect, attenuation of IL- $1 \beta$ and IL- 6 along with TNF- $\alpha$ in a dose-dependent manner, and inhibition of NF- $\kappa B$ by chlorogenic acid in a DSS-induced colitis have been reported in a recent study [79].

Although clinical practice guidelines [80] recommend that people with IBD avoid caffeine, there are more clinical and experimental evidences indicating a possible prospective effect of coffee and its components to IBS symptoms or other inflammatory diseases of the gastrointestinal tract. 


\section{Summary}

To date, there are still many misconceptions about coffee and health that can lead to confusion about whether coffee consumption can be enjoyed as part of a healthy, balanced diet. Therefore, the potential effect of coffee on the risk of many diseases has been studied intensively during the last years, sometimes with contradictory results. The acknowledgment that coffee and caffeine are not equivalent has increased the interest in whether other components of coffee might contribute to the protective action in the human body and, should that be the case, in which sense. In this case, the majority of research has mainly focused on polyphenols. Nevertheless, there is not enough information to answer this question.

It is important to note that individual differences exist in responses to coffee. Some people are more sensitive to the effects than others. Part of such variability is due to tolerance, but there are indications that it might have a genetic basis as well [81]. Another interesting fact is that males and females differ in their responses to caffeine and that these differences may be mediated by changes in circulating steroid hormones [82]. In most people, moderate coffee consumption of up to 4 cups of coffee per day (around $400 \mathrm{mg}$ caffeine) can be enjoyed as part of a healthy, balanced diet and an active lifestyle. Lower levels are recommended for pregnant women who are advised to limit caffeine intake to $200 \mathrm{mg}$ from all sources, as well as in children where the intake should be reduced because of a lower body weight [83]. Finally, there is a need for well-designed, randomized, controlled trials further investigating the effect of different doses of coffee or coffee bioactive components on healthy individuals as well as on patient populations to clarify important points discussed controversially in the literature.

\section{Acknowledgements}

I am grateful to Dr. Cica Vissiennon for helpful comments and suggestions during the preparation of the manuscript.

\section{Conflict of Interest}

The author reports no financial interests or potential conflicts of interest.

\section{References}

[1] Global coffee production, 2016/17. Available at https://www.statista. com/statistics/263311/worldwide-production-of-coffee/. Accessed May 29, 2017

[2] Dicum G, Luttinger N. The Coffee Book: Anatomy of an Industry from the Crop to the last Drop. New York: The New Press; 1999: IX

[3] Wolf A, Bray GA, Popkin BM. A short history of beverages and how our body treats them. Obesity Rev 2008; 9: 151-164

[4] Patay EB, Bencsik T, Papp N. Phytochemical overview and medicinal importance of Coffea species from the past until now. Asian Pac J Trop Med 2016; 9: 1127-1135

[5] Clifford MN. Chlorogenic acids and other cinnamates - nature, occurrence, dietary burden, absorption and metabolism. J Sci Food Agric 2000; 80: 1033-1043
[6] George SE, Ramalakshmi K, Rao LJM. A perception on health benefits of coffee. Crit Rev Food Sci Nutr 2008; 48: 464-486

[7] Higdon JV, Frei B. Coffee and health: a review of recent human research. Crit Rev Food Sci Nutr 2006; 46: 101-123

[8] Ferruzzi MG. The influence of beverage composition on delivery of phenolic compounds from coffee and tea. Physiol Behav 2010; 100: 33-41

[9] Stalmach A, Mullen W, Barron D, Uchida K, Yokota T, Cavin C, Steiling H, Williamson G, Crozier A. Metabolite profiling of hydroxycinnamate derivatives in plasma and urine after the ingestion of coffee by humans: identification of biomarkers of coffee consumption. Drug Metab Dispos 2009; 37: 1749-1758

[10] Liang N, Kitts DD. Antioxidant property of coffee components: assessment of methods that define mechanisms of action. Molecules 2014; 19: $19180-19208$

[11] Gomez-Ruiz JA, Leake DS, Ames JM. In vitro antioxidant activity of coffee compounds and their metabolits. J Agr Food Chem 2007; 55: 69626969

[12] Naidoo N, Chen C, Rebello SA, Speer K, Shyong Tai E, Lee J, Buchmann S, Koelling-Speer I, van Dam RM. Cholesterol-raising diterpenes in types of coffee commonly consumed in Singapore, Indonesia and India and associations with blood lipids: a survey and cross section study. Nut J 2011; 10: $48-58$

[13] Nathanson JA. Caffeine and related methylxanthines: possible naturally occurring pesticides. Science 1984; 226: 184-187

[14] Barone J], Roberts HR. Coffeine consumption. Food Chem Toxicol 1996; 34: $119-129$

[15] Fredholm BB, Bättig K, Holmen J, Nehlin A, Zvartau EE. Action of caffeine in the brain with special reference to factor that contribute to its widespread use. Pharmacol Rev 1999; 51: 83-133

[16] International Food Information Council Foundation. IFIC review. Coffeine \& health: clarifying the controversies. Available at www.foodinsight.org/ Content/3147/Caffeine_v8-2.pdf. Accessed May 29, 2017

[17] Schwarzschild MA, Xu K, Oztas E, Petzer JP, Castagnoli K, Castagnoli N jr., Chen JF. Neuroprotection by caffeine and more specific A2A receptor antagonists in animal models of Parkinson's disease. Neurology 2003; 61 (11 Suppl. 6): S55-S61

[18] Blum M, Demierre A, Grant DM, Heim M, Meyer UA. Molecular mechanism of slow acetylation of drugs and carcinogens in humans. Proc Natl Acad Sci U S A 1991; 88: 523-541

[19] Chan DK, Lam MK, Wong R, Hung WT, Wilcken DE. Strong association between $\mathrm{N}$-acetyltransferase 2 genotype and PD in Hong Kong Chinese. Neurology 2003; 60: 1002-1005

[20] Meyer FP, Canzler E, Giers H, Walther H. Time course of inhibition of caffeine elimination in response to the oral depot contraceptive agent Deposiston. Hormonal contraceptives and caffeine elimination. Zentralbl Gynakol 1991; 113: 297-302

[21] Ortweiler W, Simon HU, Splinter FK, Peiker G, Siegert C, Traeger A. Determination of caffeine and metamizole elimination in pregnancy and after delivery as an in vivo method for characterization of various cytochrome p-450 dependent biotransformation reactions. Biomed Biochim Acta 1985; 44: 1189-1199

[22] Chen JF, Eltzschig HK, Fredholm BB. Adenosine receptors as drug targets - what are the challenges? Nat Rev Drug Discov 2013; 12: 265-286

[23] Fredholm BB, IJzerman AP, Jacobson KA, Klotz KN, Linden J. International Union of Pharmacology. XXV. Nomenclature and classification of adenosine receptors. Pharmacol Rev 2001; 53: 527-552

[24] Paul O, Lepper MH, Phelan WH, Dupertuis GW, Macmillan A, McKean H, Park H. A longitudinal study of coronary heart disease. Circulation 1963; 28: $20-31$

[25] Sofi F, Conti AA, Gori AM, Eliana Luisi ML, Casini A, Abbate R, Gensini GF. Coffee consumption and risk of coronary heart disease: a meta-analysis. Nutr Metab Cardiovasc Dis 2007; 17: 209-223 
[26] Larsson SC, Orsini N. Coffee consumption and risk of stroke: a dose-response meta-analysis of prospective studies. Am J Epidemiol 2011; 174: 993-1001

[27] Mostofsky E, Rice MS, Levitan EB, Mittleman MA. Habitual coffee consumption and risk of heart failure: a dose-response meta-analysis. Circ Heart Fail 2012; 5: 401-405

[28] Ding M, Bhupathiraju SN, Satija A, van Dam RM, Hu FB. Long-term coffee consumption and risk of cardiovascular disease: a systematic review and a dose-response meta-analysis of prospective cohort studies. Circulation 2014; 129: 643-659

[29] Malerba S, Turati F, Galeone C, Pelucchi C, Verga F, La Vecchia C, Tavani A. A meta-analysis of prospective studies of coffee consumption and mortality for all causes, cancers and cardiovascular diseases. Eur J Epidemiol 2013; 28: 527-539

[30] Liu J, Sui X, Lavie C], Hebert JR, Earnest CP, Zhang J, Blair SN. Association of coffee consumption with all-cause and cardiovascular disease mortality. Mayo Clin Proc 2013; 88: 1066-1074

[31] Jacobson KA, Gao ZG. Adenosine receptors as therapeutic targets. Nat Rev Drug Discov 2006; 5: 247-264

[32] Jee SH, He J, Appel L], Whelton PK, Suh I, Klang MJ. Coffee consumption and serum lipids: a meta-analysis of randomized controlled clinical trials. Am J Epidemiol 2001; 153: 353-362

[33] Buscemi S, Mattina A, Tranchina MR, Verga S. Acute effects of coffee on QT interval in healthy subjects. Nutr ] 2011; 10: 15

[34] Zhao Y, Wang J, Ballevre O, Luo H, Zhang W. Antihypertensive effects and mechanisms of chlorogenic acids. Hypertens Res 2012; 35: 370 374

[35] Kim B, Nam Y, Kim J, Choi H, Won C. Coffee consumption and stroke risk: A meta-analysis of epidemiologic studies. Korean J Fam Med 2012; 33: 356-365

[36] Van Dam R. Coffee consumption and risk of type 2 diabetes, cardiovascular diseases, and cancer. Appl Physiol Nut Metab 2008; 33: 1269-1283

[37] Ding M, Bhupathiraju SN, Chen M, van Dam RM, Hu FB. Caffeinated and decaffeinated coffee consumption and risk of type 2 diabetes: a systematic review and a dose-response meta-analysis. Diabetes Care 2014; 37 : 569-586

[38] Doo T, Morimoto Y, Steinbrecher A, Laurence N. Kolonel LN, Maskarinec $G$. Coffee intake and risk of type 2 diabetes: the multiethnic cohort. Public Health Nutr 2014; 17: 1328-1336

[39] Floegel A, Pischon T, Bergmann MM, Teucher B, Kaaks R, Boeing H. Coffee consumption and risk of chronic disease in the European Prospective Investigation into Cancer and Nutrition (EPIC)-Germany study. Am J Clin Nutr 2012; 95: 901-908

[40] Loopstra-Masters RC, Liese AD, Haffner SM, Wagenknecht LE, Hanley A]. Associations between the intake of caffeinated and decaffeinated coffee and measures of insulin sensitivity and beta cell function. Diabetologia 2011; 54: 320-328

[41] Yarmolinsky J, Mueller NT, Duncan BB, del Carmen Bisi Molina M, Goulart AC, Schmidt MI. Coffee consumption, newly diagnosed diabetes, and other alterations in Ggucose homeostasis: A cross-sectional analysis of the Longitudinal Study of Adult Health (ELSA-Brasil). PLoS One 2015; 10: e0126469

[42] Bhupathiraju SN, Pan A, Malik VS, Manson JE, Willett WC, van Dam RM, Hu FB. Caffeinated and caffeine-free beverages and risk of type 2 diabetes. Am J Clin Nutr 2013; 97: 155-166

[43] Ong KW, Hsu A, Tan BKH. Chlorogenic acid stimulates glucose transport in skeletal muscle via AMPK activation: a contributor to the beneficial effects of coffee on diabetes. PLoS One 2012; 7: e32718

[44] Maalik A, Bukhari SM, Zaidi A, Shah KH, Khan FA. Chlorogenic acid: a pharmacologically potent molecule. Acta Pol Pharm 2016; 73: 851-854

[45] Fujii Y, Osaki N, Hase T, Shimotoyodome A. Ingestion of coffee polyphenols increases postprandial release of the active glucagon-like peptide- 1 (GLP-1(7-36)) amide in C57BL/6] mice. J Nutr Sci 2015; 4: e9
[46] Rustenbeck I, Lier-Glaubitz V, Willenborg M, Eggert F, Engelhardt U, Jörns A. Effect of chronic coffee consumption on weight gain and glycaemia in a mouse model of obesity and type 2 diabetes. Nutr Diabetes 2014; 4: e123

[47] Song S], Choi S, Park T. Decaffeinated green coffee bean extract attenuates diet-induced obesity and insulin resistance in mice. Evid Based Complement Alternat Med 2014; 2014: 718379

[48] Wadhawan M, Anand AC. Coffee and liver disease. J Clin Exp Hepatol 2016; 6: 40-46

[49] Liu F, Wang X, Wu G, Chen L, Hu P, Ren H, Hu H. Coffee consumption decreases risks for hepatic fibrosis and cirrhosis: A meta-analysis. PLoS One 2015; 10: e0142457

[50] Ruhl CE, Everhart JE. Coffee and caffeine consumption reduce the risk of elevated serum alanine aminotransferase activity in the United States. Gastroenterology 2005; 128: 24-32

[51] Ruhl CE, Everhart JE. Coffee and tea consumption are associated with a lower incidence of chronic liver disease in the United States. Gastroenterology 2005; 129: 1928-1936

[52] Shim SG, Jun DW, Kim EK, Saeed WK, Lee KN, Lee HL, Lee OY, Choi HS Yoon BC. Caffeine attenuates liver fibrosis via defective adhesion of hepatic stellate cells in cirrhotic model. J Gastroenterol Hepatol 2013; 28: 1877-1884

[53] Klatsky AL, Morton C, Udaltsova N, Friedman GD. Coffee, cirrhosis, and transaminase enzymes. Arch Intern Med 2006; 166: 1190-1195

[54] Hodge A, Lim S, Goh E, Wong O, Marsh P, Knight V, Sievert W, de Courten B. Coffee intake is associated with a lower liver stiffness in patients with non-alcoholic fatty liver disease, hepatitis $C$, and hepatitis B. Nutrients 2017; 9: 56-64

[55] Dranoff JA, Feld J], Lavoie EG, Fausther M. How does coffee prevent live fibrosis? Biological plausibility for recent epidemiological observations. Hepatology 2014; 60: 464-467

[56] Gressner OA, Lahme B, Rehbein K, Siluschek M, Weiskirchen R, Gressner AM. Pharmacological application of caffeine inhibits TGF- $\beta$-stimulated connective tissue growth factor expression in hepatocytes via PPAR and SMAD2/3-dependent pathways. J Hepatol 2008; 49: 758-767

[57] Arauz J, Moreno MG, Cortes-Reynosa P, Salazar EP, Muriel P. Coffee attenuates fibrosis by decreasing the expression of TGF-beta and CTGF in a murine model of liver damage. J App Toxicol 2013; 3: 970-979

[58] Furtado KS, Prado MG, Aguiar E Silva MA, Dias MC, Rivelli DP, Rodrigues MA, Barbisan LF. Coffee and caffeine protect against liver injury induced by thioacetamide in male Wistar rats. Basic Clin Pharmacol Toxicol 2012 111: 339-347

[59] Vitaglione P, Morisco F, Mazzone G, Amoruso DC, Ribecco MT, Romano A, Fogliano V, Caporaso N, D’Argenio G. Coffee reduces liver damage in a rat model of steatohepatitis: the underlying mechanisms and the role of polyphenols and melanoidins. Hepatology 2010; 52: 1652-1661

[60] Salomone F, Galvano F, Volti GL. Molecular bases underlying the hepatoprotective effects of coffee. Nutrients 2017; 9: 85

[61] Torres DM, Harrison SA. Is it time to write a prescription for coffee? Coffee and liver disease. Gastroenterology 2013; 144: 670-672

[62] Wan CW, Wong CN, Pin WK, Wong MH, Kwok CY, Chan RY, Yu PH, Chan SW. Chlorogenic acid exhibits cholesterol lowering and fatty liver attenuating properties by up-regulating the gene expression of PPAR- $\alpha$ in hypercholesterolemic rats induced with a high-cholesterol diet. Phytother Res 2013; 27: 545-551

[63] Xu D, Hu L, Xia X, Song J, Li L, Song E, Song Y. Tetrachlorobenzoquinone induces acute liver injury, up-regulates $\mathrm{HO}-1$ and NQO1 expression in mice model: the protective role of chlorogenic acid. Environ Toxicol Pharmacol 2014; 37: 1212-1220

[64] Shi H, Dong L, Bai Y, Zhao J, Zhang Y, Zhang L. Chlorogenic acid against carbon tetrachloride-induced liver fibrosis in rats. Eur J Pharmacol 2009; 623: $119-124$ 
[65] Shim SG, Jun DW, Kim EK, Saeed WK, Lee KN, Lee HL, Lee OY, Choi HS, Yoon BC. Caffeine attenuates liver fibrosis via defective adhesion of hepatic stellate cells in cirrhotic model. J Gastroenterol Hepatol 2013; 28: 1877-1884

[66] Boekema PJ, van Dam van Isselt EF, Bots ML, Smout AJ. Functional bowel symptoms in a general Dutch population and associations with common stimulants. Neth J Med 2001; 59: 23-30

[67] Kim J, Oh SW, Myung SK, Kwon H, Lee C, Yun JM, Lee HK; Korean Metaanalysis (KORMA) Study Group. Association between coffee intake and gastroesophageal reflux disease: a meta-analysis. Dis Esophagus 2013; 27: $311-317$

[68] Shimamoto T, Yamamichi N, Kodashima S, Takahashi Y, Fujishiro M, Oka M, Mitsushima T, Koike K. No association of coffee consumption with gastric ulcer, duodenal ulcer, reflux esophagitis, and non-erosive reflux disease: a cross-sectional study of 8,013 healthy subjects in Japan. PLoS One 2013; 8: e65996

[69] Loomis D, Guyton KZ, Grosse Y, Lauby-Secretan B, El Ghissassi F, Bouvard V, Benbrahim-Tallaa L, Guha N, Mattock H, Straif K; International Agency for Research on Cancer Monograph Working Group. Carcinogenicity of drinking coffee, mate, and very hot beverages. Lancet Oncol 2016; 17: 877-878

[70] Botelho F, Lunet N, Barros H. Coffee and gastric cancer: systematic review and meta-analysis. Cad Saude Publica 2006; 22: 889-900

[71] Ng SC, Tang W, Leong RW, Chen M, Ko Y, Studd C, Niewiadomski O, Bell S, Kamm MA, de Silva HJ, Kasturiratne A, Senanayake YU, Ooi CJ, Ling KL, Ong D, Goh KL, Hilmi I, Ouyang Q, Wang YF, Hu P, Zhu Z, Zeng Z, Wu K, Wang X, Xia B, Li J, Pisespongsa P, Manatsathit S, Aniwan S, Simadibrata M, Abdullah M, Tsang SW, Wong TC, Hui AJ, Chow CM, Yu HH, Li MF, Ng KK, Ching J, Wu JC, Chan FK, Sung J. Environmental risk factors in inflammatory bowel disease: a population-based case-control study in Asia-Pacific. Gut 2015; 64: 1063-1071

[72] Andersen LF, Jacobs DR jr., Carlsen MH, Blomhoff R. Consumption of coffee is associated with reduced risk of death attributed to inflammatory and cardiovascular diseases in the lowa Women's Health Study. Am J Clin Nutr 2006; 83: 1039-1046

[73] Langhorst J, Varnhagen I, Schneider SB, Albrecht U, Rueffer A, Stange R, Michalsen A, Dobos G]. Randomised clinical trial: a herbal preparation of myrrh, chamomile and coffee charcoal compared with mesalazine in maintaining remission in ulcerative colitis - a double-blind, doubledummy study. Aliment Pharmacol Ther 2013; 38: 490-500

[74] Vissiennon C, Hammoud D, Rodewald S, Fester K, Goos KH, Nieber K, Arnhold J. Chamomile flower, myrrh, and coffee charcoal, components of a traditional herbal medicinal product, diminish proinflammatory activation in human macrophages. Planta Med 2017; 10: 846-854

[75] Lee IA, Low D, Kamba A, Llado V, Mizoguchi E. Oral caffeine administration ameliorates acute colitis by suppressing chitinase 3-like 1 expression in intestinal epithelial cells. J Gastroenterol 2014; 49: 1206-1216

[76] Mizoguchi E. Chitinase 3-like-1 exacerbates intestinal inflammation by enhancing bacterial adhesion and invasion in colonic epithelial cells. Gastroenterology 2006; 130: 398-411

[77] Rubach M, Lang R, Seebach E, Somoza MM, Hofmann T, Somoza V. Multi-parametric approach to identify coffee components that regulate mechanisms of gastric acid secretion. Mol Nutr Food Res 2011; 56: 325-335

[78] Zatorski H, Sałaga M, Zielińska M, Piechota-Polańczyk A, Owczarek K, Kordek R, Lewandowska U, Chen C, Fichna J. Experimental colitis in mice is attenuated by topical administration of chlorogenic acid. Naunyn Schmiedebergs Arch Pharmacol 2015; 388: 643-651

[79] Hwang SJ, Kim YW, Park Y, Lee H], Kim KW. Anti-inflammatory effects of chlorogenic acid in lipopolysaccharide-stimulated RAW 264.7 cells. Inflamm Res 2013; 63: 81-90

[80] Brown AC, Rampertab SD, Mullin GE. Existing dietary guidelines for Crohn's disease and ulcerative colitis. Expert Rev Gastroenterol Hepatol 2011; 5: 411-425

[81] Coffee and Caffeine Genetics Consortium. Genome-wide meta-analysis identifies six novel loci associated with habitual coffee consumption. Mol Psychiatry 2015; 20: 647-656

[82] Temple JL, Ziegler AM. Gender differences in subjective and physiological responses to caffeine and the role of steroid hormones. J Caffeine Res 2011; 1: 41-48

[83] European Food Safety Authority. EFSA Panel on dietetic products, nutrition and allergies (NDA). Scientific opinion on the safety of caffeine. EFSA Journal 2015; 13: 4102-4107 